\title{
Ambivalent Ghosts: The Manifestation of the Supernatural in Ruth Rendell's Fiction
}

\begin{abstract}
This article examines the supernatural in Ruth Rendell's fiction. Rendell was fascinated by the supernatural and returned to it throughout her writing career. The essay begins by looking at the manifestation of ghosts as a symptom of domestic entrapment. These ghosts are an extension of women's curtailed and claustrophobic lives. It then explores the depiction of mediums and soothsayers which, although allowing more agency for women still leaves unresolved slippages between the real and the not-real. The article ends by looking at Rendell's haunted men arguing that there is a relatively conventional expansion of the imagination for men who become aware of the possibility of the supernatural. The article argues that the gender divide apparent in Rendell's depiction of ghost-seeing and occult practices provides the critique of conventional gender roles and expectations which is so much a part of all her work. However, the role the supernatural plays in her fiction goes further and expresses an apparent doubt that Rendell feels about the actual materiality of ghosts and the efficacy of occult practices. Rendell's treatment of the supernatural is insistently ambivalent. This article argues that for someone who states so clearly: "I don't believe in ghosts" (The Guardian, 2012), surprisingly Rendell continuously refuses to dismiss them.
\end{abstract}


In the menacing Gothic novella Heartstones, Ruth Rendell quotes Henry Fielding's advice to authors. He cautions them to be careful in the use of any sort of paranormal phenomena: "[t]he only supernatural agents which can in any manner be allowed to us moderns are ghosts but of these I would advise an author to be extremely sparing. They are indeed like arsenic and other dangerous drugs in physic, to be used with the utmost caution" (11). Rendell herself follows this prescription and supernatural agents are rare in her work. Yet when they do appear they form a significant presence. Best known for her crime fiction and her psychological thrillers, the idea of the supernatural, the paranormal, or ghosts making any sort of appearance in Rendell's work may seem anomalous. However, she has always been interested in the supernatural and early in her writing career, when working as a journalist, she invented a story about a local house being haunted. The owners of the house threatened to sue because of a possible devaluation in the house price, Rendell was sacked from the paper and this propelled her into fiction writing.

Throughout her writing career Rendell has explored the supernatural, questioning whether it is real or if it only exists in the mind. Rendell herself seems to half-believe in the supernatural although she says; "I don't of course believe in ghosts" (The Guardian 2012). Yet ghosts, haunting, the other-worldly and the supernatural in various manifestations are subjects that she comes back to again and again with an uncomfortable semi-belief that seems to trouble her. This essay looks at the representation of the supernatural in three genres of Rendell's writing: the stand-alone psychological thrillers, detective fiction and the Wexford series and the only two actual ghost stories that she wrote, "The Haunting of Shawley Rectory" (1979) and "The Green Road" (1981).1 Rendell presents the supernatural slightly differently in each genre and gender plays a part in ghost-seeing and occult practice. In the psychological thrillers the presence of the supernatural signifies domestic entrapment and ghost-seeing is an 
extension of women's narrow and curtailed lives and an effect of psychosis or schizophrenia. This is particularly true for Dolly in Killing Doll (1984) and Minty in Adam and Eve and Pinch Me (2001). However for women who deliberately undertake occult practices; who are mediums or soothsayers, the supernatural provides more of a release from oppression. Here the occult can guard against mental illness and is incorporated into "normal" life for both Lena in The Lake of Darkness (1980) and Shoshana in Thirteen Steps Down (2004). In these stand-alone thrillers Rendell questions the divide between the mind and the material world. Although many of her ghost seers are psychotic or delusional, there is ambivalence in her representation of the supernatural and she leaves open the question of whether it may, in some forms, actually exist. Yet there is no sensationalism here. Rendell is fascinated by the ordinary, the banal and the everyday and the supernatural depicted in these novels is tightly interwoven with the ordinariness of women's mundane lives.

In the introduction to The Virago Book of Victorian Ghost Stories, Jennifer Uglow notes "how the experience of seeing a ghost pushes men into conventional female roles: timid, nervous and helpless" (xvii). Rendell explores this apparent feminization in the seemingly logical and rational men who experience the supernatural. For Reg Wexford, in The Speaker of Mandarin (1983), ghost-seeing both questions and enhances his detecting powers. Wexford is an intuitive man and seeing ghosts stretches this intuition to its limit, but ultimately he gains in sensitivity and empathy. In the two ghost stories, "The Haunting of Shawley Rectory" and "The Green Road" the men who experience supernatural occurrences encounter a material slip between the imagination and the real. And for both there is an expansion of consciousness and an opening of the mind to other possibilities. Rendell refuses to decide about the 'reality' of the supernatural and while she uses it to explore gender relations and other social concerns, ultimately it is her own ambivalent attitude to the 
supernatural that is played out through her fiction. She teases at the supernatural, and seemingly it teased at her too.

Rendell's evocations of the supernatural are deceptively insignificant in scale and often quite banal. It is in small, dull, narrow lives, that the effects of any sort of supernatural phenomena, real or imagined, reverberate. Rendell says of M. R. James that he has a "genius for the art of understatement" (vii), and she herself is not given to over-statement in relation to the supernatural. In 1987 Rendell selected and edited a collection of ghost stories by James, and in the introduction she argues the following:

Fiction concerning the supernatural falls into two categories. There is the first kind, in which the works of Ann Radcliffe, that mistress of the Gothic novel, naturally find a place. Here everything which happens is capable of a rational explanation. In more recent times apparently paranormal events in fiction are usually attributed to hallucination on the part of the witness, to dreams or even schizophrenia. Then there is the second category where it is accepted that the supernatural does exist and that there are indeed more things in heaven and earth than are dreamt of in any rationalist philosophy. (1987, xii)

Rendell never seems to quite resolve this dichotomy. In the stand-alone thrillers where actual ghosts appear, there is always a rational explanation: the ghost seer is psychotic or it is not really a ghost but a misapprehension. In these tales what is real and what is illusion/delusion is clear cut. Paradoxically, when characters in these thrillers actually see ghosts, there are inevitably no ghosts to be seen: they do not exist. Yet in the ghost stories mentioned above, in the Wexford story and in the substrate of her exploration of the supernatural which deals with clairvoyance, soothsaying and mediums, the lines are in no way so clearly drawn. Here, the 
"second category" of supernatural fiction creeps in unannounced and the possibility of the reality of something else occupies a shadowy corner.

\section{Ghosts, Women and Domesticity}

Although rare, ghosts are important in Rendell's work and there is often a gender divide involved in ghost-seeing. Most of the ghosts that women have to contend with in her novels are dull, annoying, dead relatives who chatter incessantly. These domestic ghosts all occur in Rendell's stand-alone psychological novels. Susan Rowland aligns these thrillers with the Gothic genre suggesting that; 'Rendell's typical narrative is to show conventions of romance as inadequate to contain the extremities of desire, so the Gothic emerges in the modification of generic boundaries' $(2001,133)$. Rendell uses the Gothic genre to highlight domestic entrapment and the claustrophobia of women who are unable to express any sort of desire. Ghosts appear to women whose lives are constructed around and constricted by a warped conception of convention.

Rendell's ghost-seeing women are trapped in the most conventional, dull and narrow of all domestic circumstances and the ghosts they see reflect this. Rendell portrays this type of domestic confinement as almost inevitably leading to psychosis and paranoid delusions. These ghosts are an extension of the narrow domestic existence that these women endure. Minty in Adam and Eve and Pinch Me and Dolly in Killing Doll, are profoundly isolated. Their lives are similar; extremely limited, curtailed and narrow; stuck in some sort of postwar idea of how women should live. Minty's life revolves around her auntie who is moralistic and desperately old-fashioned and Dolly's around her mother who is prim and overprotective. Minty's auntie and Dolly's mother die and quite soon afterwards both women 
begin to see ghosts. These are not grand, terrifying ghostly manifestations, rather they are bothersome, aggravating hauntings and the ghosts are concerned with trivial domestic details. For Dolly and Minty, their ghosts crowd in on them, badgering them about their domestic arrangements. In Adam and Eve and Pinch Me, as Minty's psychosis deepens she begins to be haunted not only by her fiancé and auntie, but also by her fiancé's mother, Mrs Lewis. Minty cleans her house incessantly and now she has the ghosts of her auntie and Mrs Lewis watching:

The two of them [were] muttering somewhere in the background. She'd just have to put up with it until they got tired and went back to wherever they came from. They wouldn't like her hoovering, the noise would drown out their voices....

Auntie started as soon as Minty took the clean yellow duster out of the kitchen drawer. "I hope you're not going to use that before you've done the floor. I don't know how many times I've told her, Mrs Lewis. It goes in one ear and out the other." "Might as well talk to a brick wall," said Mrs Lewis, for by this time Minty had begun removing all the ornaments on the little table and spraying the surface with liquid wax. "That stuff she's using just swallows up the dirt and leaves a nasty deposit". $(250)$

Minty is hounded and tormented by her ghosts; they berate and scold, acting as a critical, petty, inconsequential conscience, giving unwanted advice about cleaning techniques and products.

Dolly's ghosts are very similar. She is haunted by her mother, Edith, and step-mother, Myra neither of whom will leave her alone. Dolly is a dressmaker and goes to start on a garment for her younger brother Pup who has decided to become an adept at magic: 
Myra followed her back into the living room. Edith was already there, waiting....

"You want to pin that silk on to a piece of flannel before you start cutting," said Edith. Myra gave one of her laughs.... Dolly sat in the window, stitching the neckline of the golden robe. They did not speak to her again, but for a long time she heard them laughing softly and their footsteps as they walked about the room. (164-5)

Dolly's ghosts gossip and criticise, discussing her dressmaking skills and her birthmark which they label as her "disability" (204). For Dolly, as for Minty though, there is no no escape from their domestic, claustrophobic horizons and this narrowness is part of their psychosis. Their ghosts originate from limited and curtailed lives, scrutinise and disapprove of the way they conduct their domestic chores, housekeeping and dressmaking. Not dramatic or horrific hauntings, but tormenting, relentless visitations which are a terrible mix of the prosaic and the fantastical.

Rendell is not the only contemporary novelist to have small, domestic hauntings. Catherine Spooner argues that in Hilary Mantel's Beyond Black, two worlds - spirit and material overlap. She says " $[\mathrm{t}] \mathrm{he}$ interpenetration of the two worlds comes as no surprise; each is as boring as the other. The spirits themselves are just as banal as their living counterparts" (Spooner 83-4). These mundane hauntings and boring spirits are of the same type that we see in Rendell's work. The domestic, the everyday, the trivial is of concern. Mantel is writing later than Rendell and she is aware of her work, writing a review of a collection of Rendell's stories as early as 1987.2 There are certainly cross-overs in how both authors depict the dead. Alison the ghost-seer and medium in Beyond Black, is surrounded by ghosts who hound and torment her, but who are at the same time banal and unimaginative. After "an exhausting hour tussling with an old corpse in a sheet" Ali reflects that "[t]he dead are like that; give them a cliché, and they'll run to it. They enjoy frustrating the living, spoiling their beauty 
sleep. They enjoyed pummelling Al's flesh, and nagging at her till she got earache" (41). Alison's ghosts roll around in old sheets and carp at her incessantly. Rendell's ghosts are similar. The ghost of Minty's auntie insists on giving her opinion to Minty, even when she doesn't expect it: ““[t]here are more and more murders about these days,' Auntie's voice said suddenly. 'I don't know what the world's coming to. They're all in gangs them as gets murdered, murdered by other gangs"” (211). Both Minty and Dolly are subjected to such banalities and narrow minded, prosaic opinions. Dolly's dead mother badgers her about the weather whispering in her ear "I never did like a wind" (128) and airs her views on "homos" asserting "it's the mothers make them that way. I read an article" (200). These are unbearable hauntings that accentuate the narrowness of their lives. In the bathroom, in the kitchen, at the bus stop, there is no escape for Minty. Dolly's ghosts murmur in her ear, sit on the end of her bed and whisper about her in the corner of her bedroom. These ghosts are like bad friends or intrusive relatives. As Minty says, they know everything, and there is no escaping them; they invade psychic and personal space and private corners of the home and even the body. This is intimate haunting which is personal, physical and psychological.

The ghosts that Minty and Dolly see are not real, but a manifestation of the growing psychosis of both women. In Rendell's work the slip into psychosis and delusion is not often portrayed as dramatic rather she is more likely to envisage it as originating from an excess of domestic banality. For Rendell, the clichéd, the mundane, the obsessive focus on the inconsequential, inevitably lead to insanity and violence. Alison's ghosts in Mantel's work have been cited as being "fairly classical manifestations of the uncanny in a Freudian sense: as revisitations of the repressed, intrusions of an un-reprocessed past into the unsuspecting present" (Funk 156). However, although so similar to Alison's ghosts and the spirits she conjures up in her work as a medium, Dolly and Minty's ghosts are more of an extension of 
repression than a revisitation or a return. Alison cannot leave behind her appalling childhood, and has to work it through with her mediumship and her interaction with her ghosts (literal and metaphorical). Minty and Dolly's repressions however do not represent an abyss of violence and abuse, but a hemmed-in, claustrophobic, constricted, blinkered-nothingness of wasted lives. Their ghosts are concerned with surfaces, with appearances and their advice consists of urging Dolly and Minty to exhibit increasingly conventional, stereotypically feminine traits and behaviours. Cleanliness, chastity, domestic skill, meekness and obedience are demanded by the ghosts that haunt Minty and Dolly. But where there is such constriction and repression there will be consequences. Alison overcomes the bloody violence of her past but Minty and Dolly are themselves the murderers; it is they who commit the violence, forced into defensive aggression. Dolly kills for company, fearful that she will lose the only chance she has of friendship. Minty, by contrast, wanting to be left alone, stabs those she believes to be ghosts; finally and unintentionally killing two people. Wolfgang Funk suggests that Alison's ghosts "foreshadow the future, a possible new configuration of human understanding of itself and/in the world, where it is no longer necessary to know everything and therefore again possible to believe in something" (157). Minty and Dolly's ghosts do not point to a new, expanded understanding of the self or the world. These ghosts represent a final limitation; a crushing level of belief that leads to an ending where no future is possible.

\section{Mediums and Clairvoyants}

Rendell's critique of the constriction of women's domestic lives shifts in relation to the subject of our next examination: the practice of clairvoyancy and mediumship. Here although it is still most often women who deal with the paranormal, occult practice offers some relief from the narrowly defined domestic. And interestingly it is here that the ambivalence about 
the un/reality of paranormal phenomenon becomes more apparent as Rendell's semi-belief is played out.

There are mediums or clairvoyants in three of her novels: The Killing Doll, The Lake of Darkness (1980) and Thirteen Steps Down (1984). In the same way that her ghosts are ordinary and prosaic, Rendell's depictions of those who deal in the supernatural and the occasions where people gather for occult meetings or readings are of the most everyday and banal sort. However, in the same way as Victorian Spiritualist practice, these meetings and rituals offer comfort and provide space for women to express themselves away from rigidly conscribed gender roles. Alex Owen who makes a fascinating and extensive study of female mediumship in Victorian times argues that although it still celebrated "'innate' feminine qualities ... Spiritualist mediumship [also] promoted a species of feminine power" (8-9). Rendell concentrates on the empowerment that mediumship and occult practice can offer women. The women who engage in these rituals are afforded more autonomy and space than Minty and Dolly and their harassing domestic ghosts. Yet here too the supernatural retains a "homely" feel and the mediums and soothsayers manage to incorporate the supernatural and the occult into their everyday lives. In Spiritualism and British Society Between the Wars, Jenny Hazelgrove argues that Spiritualist practice offended "psychical researchers and occultists" who she says deemed that, "[c]osmic reality apparently deserved more dignity than Spiritualism offered, with its homely setting, mundane messages, anthropomorphic and grossly materialistic version of the afterworld" (272-3). Death, life after death, revenants and ghosts should be significant. Yet, in fiction and in fact, many encounters with the "other side" (real or imagined) are seemingly inconsequential. 
In the short, powerful novel The Lake of Darkness, the schizophrenic Lena finds sanity and a safe space for herself within occult practice. In this novella raising the spirits of the dead, consulting an Ouija board, reading tarot cards all guard against, and form a barrier to the psychosis experienced by such women as Minty and Dolly. We follow the fortunes of the murderous Finn, an aesthete and an adept. Lena, who is Finn's mother, has never been mentally stable, but he loves her and reflects that "[ $\mathrm{t}]$ hey had been through so much together, he and she, fighting the world, exploring the unseen, approaching strange spiritual agents (923). Lena and Finn have explored the occult and unseen worlds together. Lena is a psychic and they both believe her to be a reincarnation of Madam Blavatsky. Throughout his childhood Finn was surrounded by "a wild poltergeist activity" (12) and belief in the supernatural and occult is embedded in their lives. In this novel, the real and the imagined, the sane and the not-sane, the supernatural, the absurd, violence and death are all mixed up in a powerful narrative that explores some very dark places. Yet for Lena, and to a certain extent Finn, occult practices represent the normal and the sane.

As Lena recovers from a psychotic episode she resumes her social life which consists of friends coming round for friendly séances or cosy sessions on the Ouija board. Finn is relieved to know that:

[1]ater on Mr Beard who kept the fur and suede cleaner's shop in Brecknock Road and who had once tried, with some success, to raise up the spirit of Cornelius Agrippa, was coming round and bringing his Ouija board. Finn felt a quiet relief that things were getting back to normal. (143)

In this household of the insane and the murderous, gentle, harmless occult practices stave off violence and psychosis and these beliefs and practices represent the everyday, the ordinary 
and, in a peculiar way, sanity. There is some sort of salvation in what Finn refers to as "the innocent pleasures of planchette" (164).

Dolly in The Killing Doll also looks to the occult for comfort and after her mother, Edith, dies, she decides to attend the Adonai Spiritist church. At the first meeting the spirit of her mother "speaks" to her through the medium in soft, slightly pompous tones:

Edith had never spoken like that. Dolly felt indignant that the medium should be such a fraud, callously deluding people, and then, simultaneously with that thought, there came to her a breath of perfume, of lemon verbena. She almost cried out, so powerful for a brief moment was this scent of her dead mother. (Killing Doll 33)

Dolly later realises that the lemon scent is worn by a woman sitting near her. However the experience has had such a profound effect on her that the ridiculousness of the séance fades in her mind. Dolly returns several times and sees the spirits of the dead conjured up and during one of these manifestations, "[i]t suddenly struck Dolly, for the first time it truly came to her, how terrible and wonderful it was, how it changed your whole life and way of looking at things, to have spirits brought to you thus from the abode of the dead" (141). In this cold hall, with people who were "ordinary, middle-aged, working-class" (ibid) Dolly’s world seems to expand. With a real life of isolation, where she is "house-bound, withdrawn" (32), access to the dead appears to open up new dimensions for Dolly.

In Phantasmogoria Marina Warner suggests that séances are a manifestation of a yearning "for an immortal and metaphysical dimension to human life - not the survival in other people's memories, but survival itself, as a wraith, as a spirit" (306). The spirits Dolly sees at the Spiritist meetings are quite material, part of the "grossly materialistic version of the afterworld" that Hazelgrove identifies in Spiritualist belief and practice (273). At one meeting 
a sheet-wrapped apparition touches Dolly and her brother, clasping their hands, but when "Pup raised himself up to look more closely... their hands were relinquished and the shape retreated" (Killing Doll 92). To the reader of course this is unsurprising; the fraud evident. Yet it is from one of these fraudulent, tacky, parochial meetings that Dolly leaves with the ghost of her step-mother, Myra, whose ghostly voice tells her, "I may as well walk home with you, Doreen" (144). The suggestion is, of course, that Dolly is having a breakdown. Yet throughout Rendell's work there lingers a question about the reality of the supernatural and whether intention (to raise the dead, to do magic) can have real consequences.

Dolly's brother Pup, for a short period during his teen years, practices magic. When their father marries again quite soon after their mother's death, Dolly, filled with jealousy, persuades Pup to perform a ritual to hurt Myra. By this time Pup does not believe in magic at all, but although he is bored, he makes a show with a type of Voodoo-doll and recites some jumbled Latin phrases to please Dolly. At the culmination of the rite:

Pup plunged forward ... and thrust the dagger's point through the belly of the doll with a sure stroke. For a moment or two the doll remained impaled on Pup's dagger and he had to draw it off with his other hand. Some of the stuffing came out and a fat worm of cotton wool like an entrail. (127)

Almost instantly after this absurd performance; "from immediately below them came a slither and a heavy thud" (128). Myra has died in the bathroom downstairs whilst attempting to perform a home abortion. One event follows the other seamlessly and although there is a rational explanation of pure coincidence, the two events remain inextricably linked and the possibility of cause and effect remains. 
In Thirteen Steps Down, the (mostly) fraudulent medium Madam Shoshana goes on an outing with some friends:

The water diviners, filing down a side street in Kilburn towards a mews under which they were told an ancient stream still flowed, chatted pleasantly to each other on such familiar subjects as astrology, cartomancy, exorcism, numerology, the Tarot, ailurophilia, hypnotism, the cult of Ashtaroth and leprechauns. (253)

There is of course humour here, however there is also an acceptance that these beliefs exist and an acknowledgment that in certain circles discussing such things is perfectly ordinary. It is this mixture of the commonplace and the fantastical that defines all Rendell's forays into the supernatural realm. Madam Shoshana is ostensibly a mercenary fraud. Rendell tells us:

[s]he herself was a curious mixture of a ribald derision of all things occult and a certain credulousness. That small leaven of faith had to exist for her to follow her chosen path in life. For instance, she had no doubt about the efficacy of waterdivining and the value of exorcism among other rituals. But she was fully in favour of helping things along with practical aids.

But yet ... These "but yets" were not insignificant in her interpretation of her vocation. The fortunes she told were based on nothing more than her imagination and her observation of human beings. What the stones did or the cards showed was irrelevant. Her ignorance of crystallomancy was profound and her knowledge of divination by cards non-existent. Yet it was strange, it was a little uncanny, how often her predictions came close to the truth. (157-8, ellipsis in the original) 
This lingering "but yet" seems to haunt Rendell too. Some of Shoshana's predictions are surprisingly accurate and there seems to be genuine insight amongst the exploitation of her clients' credulity and her undoubted greed.

Mix, the narrow-minded, dull, boring, violent, ghost-seeing antagonist of the novel annoys Shoshana and she decides to get some sort of revenge. She consults her friend Hecate the witch who offers to send her a spell and tells her in an email: "It's a very effective one that cramps the object's spinal column and lasts up to one week, though it is renewable" (258). There is again humour here and absurdity. However, a short time after Shoshana has decided to try out the spell we hear: "[b]ackache woke [Mix] in the small hours. It was so bad that he groaned aloud.... The backache was felt as if it was there to stay and it was far worse than the last time. It seemed to affect his whole spine" (288-9). Mix has already incurred a bad back by digging a grave for the girl he has murdered. Yet there still remains a question as to whether Shoshana's spell "worked" in the same way that there is a question over whether Pup and Dolly's voodoo doll ritual helped to kill Myra. Throughout her work there is ambivalence in Rendell's portrayal of the supernatural. Rendell does not resolve the issue of the supernatural, and the connections between cause, consequence, effect, intention and reality remain equivocal.

\section{Haunted Men}

In the discussion above, we have looked at female characters who see ghosts and deal in the occult. For Dolly and Minty, their experience of the supernatural was an extension of their repression and their ghosts manifested in their minds. However the occult practices that women engage with provide some sort of bridge between the imagination and the material world. And in this way these practices offer at least some hope for an expansion of women's horizons. In this section we look at how the supernatural manifests to men: Rendell's 
detective, Reg Wexford and the male narrators of the two stories that sit in the ghost story genre. In these cases 'reality' obtrudes still further and the question of insanity recedes. 3

In Murder by the Book Sally Munt begins with a description of the "detective hero":

He is the representation of Man, and yet more than a man, he is the focus of morality, the mythic hero. He is the controlled centre surrounded by chaos, and an effective reading must involve identification with this mediator of action, truth, and finally pleasure and relief through closure. Both form and the content of this scenario are iconically masculine. (1)

Reg Wexford can be described as the "detective hero" of Rendell's long running detective series. He is physically reassuring - big and stolid - whilst also being ethical, moral and straightforward. He inspires trust in the reader and there will be closure at the end of each Wexford novel. Yet, in Rendell's inimitable way, this will also be undercut. Wexford sees a ghost in The Speaker of Mandarin. The "ghost" he sees is of an old Chinese woman with bound feet, but he has other visions too and he has a nightmare about the ancient corpse of the Marquise of Tai that he had seen in a museum. A few days later, on a train, he goes to his compartment and slides open the door:

In the right-hand berth, on her back, her striated pinkish-white legs splaying from under the white shift, her face white and puffy, the bridge of her nose encaved, the mouth open and the tongue protruding, lay the Marquise of Tai....

He didn't cry out or even gasp. He closed his eyes and held his fists tightly clenched. Without looking again at the dead thing, the mummified, two-thousand year old thing, he turned swiftly and went out into the corridor. (44-5) 
Most of the other visions Wexford experiences are able to be explained. The mystery of the apparition of the woman with bound feet is resolved; there is a real elderly Chinese woman stalking Wexford's tourist party, Wexford himself is over-wrought, reading ghost stories and drinking too much green tea. However the explanations do not quite cover all the visions and manifestations. When Wexford see the corpse of the Marquise of Tai he is awake and has just washed his face and hands (actions which supposedly make one alert). Wexford himself reflects on his vision; "[t]here was no doubt of what he had seen. The corpse had been lying there. ... He knew he had seen it" (46 emphasis in original).

Susan Rowland says that in this novel,

the terrifying Gothic sublime lies in the temporary annihilation of categories of knowledge. Detecting does restore the categories, but this sublime is not simply the 'other' to be excluded from the detecting narrative. Rather, the Gothic persists within the detective's superior mental powers. (The Devil Himself 140, emphasis in original)

Rowland argues that for Wexford, the dark insights of the supernatural and the Gothic are a part of his detecting power. Ghost seeing, an awareness of something other than or beyond the rational, elevates him and makes his detecting powers almost mystical. Elsewhere she has argued that,

it is unsurprising that the self-conscious artifice of the golden age genre (and its continued existence within the works of James and Rendell), should construct the detective as a metaphysical figure whose potency for restoring social order is reinforced by the trappings of neo-divine power. (The Spirits of Detection 191-2)

In The Speaker of Mandarin the supernatural enables Wexford to circumvent the overmasculinization of the "detective hero" and affords him new power. And while these are the 
only ghost figures in the series, his continued knowledge of the metaphysical realm enhances his intuition until it nearly resembles a kind of clairvoyant insight.

This question of enhanced insight for men who experience the supernatural pervades the only two ghost stories Ruth Rendell wrote: "The Green Road” and "The Haunting of Shawley Rectory". The ghost story has often been categorized as a female genre and, particularly in relation to Victorian ghost stories, discussed as allowing space for agency for women and criticism of patriarchal, domestic oppression.4 Ghost stories often criticise narrowmindedness and the over-logical rationality of men and whilst Rendell's ghost stories conform to this critique, they also offer the men who experience the supernatural experience an expansion of consciousness and insight. Rendell's men are initially more sceptical than her women. A statement near the beginning of "The Green Road" appears to be unequivocal: our narrator tells us, "'this is not a ghost story" (46). Yet as soon as one is told this, it becomes apparent that the tale to come will be a ghost story. The first sentence of "Shawley Rectory" reads; “I don't believe in the supernatural, but just the same I wouldn't live in Shawley Rectory" (374). The same belief-and-at-the-same-time-disbelief that Rendell ascribed to the medium Shoshana, (with her mixture of "derision" and "credulousness"), characterizes these two stories. Both of Rendell's ghost stories are about haunted places: a house and a green road and haunted people; those who encounter the uncanny in these places. These are both inner and outer spaces; psychological and material. There is a green road that traverses the imagination and which manifests itself (for a short while) in the "real" world, and in "Shawley Rectory" there is an animated house which itself pervades the psyche and forces perceptions of haunting onto its inhabitants. In both stories there is deliberate ambiguity and a blurring of boundaries between the real and the unreal, the material world and the psyche, belief and disbelief, the body and the mind. 
The narrator of "The Green Road" asks: "[w] ho could conceive of the ghost, not of a person but of a place, and that place having no existence in the natural world?" (46). Yet finally, through the haze of his initial disbelief, he can and does conceive of this ghost of a landscape. The green road in question is the imaginative creation of our narrator's friend, a novelist called Arthur. After leaving Arthur's house, (where unknown to him Arthur has hung himself), the narrator walks for a while on the ordinary disused railway track. Suddenly he sees a track leading off to the side: "[i]nstead of the gardens and backs of houses which I expected to see, there stretched before me, long and straight and raised like a causeway, a green road. ... I stood staring at it in wonder. How could it be that I had never noticed it before (56). He had not noticed it because this is the only time that it will exist in the material world. At this moment, the green road is a physical, material road which appears just for him, just this once. He steps onto the road and walking on it is an intensely physical experience:

tall trees grew on either side of the path, oaks and beeches such as were never seen on the other line, and ahead of me their branches met overhead and their fine frondy twigs interlaced. Around their trunks I at last saw the foxgloves and the tansy Arthur had spoken of, and the further I went the more the air seemed perfumed with the scent of wild flowers.

... It was growing late in the afternoon and a mist was settling over London as often happens after a warm day in late summer or early autumn. The slate roofs, lying a little beneath me, gleamed dully silver through this sleepy, gold-shot mist.... No bird sang and no breeze ruffled the feather-light, golden, downy, sweet-scented tufts of the mimosa flowers. (118)

The narrator is walking in this landscape; feeling, seeing, smelling. This ghostly, haunted place immerses him and he becomes part of it. Boundaries between life and death, the 
immaterial and the material, the natural and the supernatural have been dissolved and our narrator's perception enhanced.

In "Shawley Rectory" there is a similar disintegration of the expected limits to reality and borders of the imagination. Here though, rather than a healing, empathetic encounter, there is violence, terror and death. The imagined green road pervades the narrator's mind and manifests in the material world allowing him to travel down it. Shawley Rectory also invades the mind, but it affects the body in a very different manner. To begin with there is just the legend, the rumour of the Rectory as a haunted house. The newly appointed Rector's wife had been told to expect "manifestations":

Ghosts! I ask you - people believing things like that in this day and age. And then we moved in and I heard them too.

The crunch of carriage wheels on the gravel drive when there was no carriage or any kind of vehicle to be seen. Doors closing softly when no doors had been left open. Footsteps crossing the landing and going downstairs, crossing the hall, then the front door opening softly and closing softly. (376)

Kate, the Rector's wife, experiences the haunting. There are sounds that move through the space of the house and the drive. However, Kate and her family, although they are witnesses of the ghosts of the house, are not the ones who will experience the full force of the house's supernatural power. The haunting of Shawley Rectory is not apparent to everyone. Our (once again unnamed) male narrator for example, spends the obligatory ghost-hunting evening there with a friend, a good bottle of brandy and a healthy dose of scepticism. As they sit waiting for the manifestations to occur, they hear the pattering of small feet and he tells us: 
It had never occurred to me even once that I should be so dreadfully, so hideously, afraid. ...

I felt myself go white, the blood all drawn in from the surface of my skin, as I was gripped by that awful primitive terror that has nothing to do with reason or with knowing what you believe in and what you don't. (386)

Our narrator is affected through his body and if he is not entirely feminized by the experience the "primitive terror" he experiences is a bodily terror that rips apart reason and embodies belief. Alan Peterson writes that; “[t]he privileging of the 'mind' over the 'body' is widely seen to be characteristic of 'masculinist' rationality" $(1998,17)$. Yet this dichotomy is very often blurred in Rendell's exploration of the supernatural. As we have seen her female mediums and occult practitioners may well exercise imaginative control over the material world whilst here our narrator's body exceeds any rationality and logic his mind may seek to hold on to. Despite his extreme bodily reaction, in this case, the pattering feet belong to a cat and in all the time they are in the house nothing supernatural occurs for them at all.

In fact, they were never going to witness the ghosts. A tragedy occurs in the house; a mother kills her daughter. Afterwards our narrator says that he believes that:

The Rectory was waiting for the right people to come along, the people who would fit its still unplayed scenario, the woman of forty, the daughter of nineteen, the lover. And only to those who approximated these characters could it show shadows and whispers of the drama; the closer the approximation, the clearer the sounds and signs. (390 emphasis in original)

In this story, the house invades the psyche of those it wants to enact its drama. There is a similar shift or slippage between the material and the immaterial, reality and the imagination, 
the mind and the body, as in "The Green Road". However, where the road manifests itself outwardly; into a traversable walkway, the Rectory manifests itself inwardly, into the psyche of the murdering mother. Manuel Aguirre talks about Shirley Jackson's Hill House as a predator. He claims that there was a change in the nineteenth century in how haunted spaces were depicted, and that this change continues in contemporary representations of haunted places. He says "[t]he first thing we learn about the modern Haunted House is that it is alive. It is not just inhabited by some ghostly presence, as Otranto was: rather, the force that lurks in it is part of the house itself' (190, emphasis in original). Just before the tragedy occurs the narrator passes the Rectory; "[I] looked back at the Rectory. It stared back at me. Is it hindsight that makes me say this or did I really feel it then? I think I did feel it, that the house stared at me with a kind of steady insolence" (389). This again is beyond rationality. Shawley Rectory is an animate house, insolent and brooding: it squats and waits for its perfect victims. The house bides its time until exactly the right people with the correct set of relationships cross its threshold; then it acts. Aguirre maintains that:

The house in Modern terror fiction is not a haunted but a haunting house. It is no longer a human space; it does not happen to be sheltering a numinous presence, it is the numinous presence, an otherworldly living space that craves birth, sustenance, growth, reproduction in the human world. It is the perfect parasite. (192 emphasis in original)

The influence of Jackson's The Haunting of Hill House is apparent in Rendell's stories where the reality/veracity of the haunting remains undecided and open to interpretation. The barriers between the imaginative subjective witnessing and the material and objective reasoning slip away and as in Hill House there is no real resolution. 
The Rectory, in a similar manner to Hill House bends and distorts the linearity of space/time as well as the boundaries between the material and the psyche. Aguirre says of Hill House; "[1]ike so many modern haunters, it does not simply destroy its victims, it changes them" (190, emphasis original). When the modern version of the tragedy occurs, Shawley Rectory invades the mother's psyche so thoroughly that it seemingly forces her to act. The mother tells a neighbour that when her daughter told her that she had taken her lover, "she felt nothing, no shock no hatred or resentment, no jealousy. It was as if she were impelled by some external force to do what she did - take the gun she always kept with her from a drawer in the writing-desk and kill her daughter" (390). There appears to be no volition on the mother's part. She is "impelled" to act, and the (very strong) suggestion is that it is the house that is forcing her to kill her daughter. After the tragedy the narrator reflects and is dismayed to find that his friend, who has a wife coming up to forty years old, and a daughter near to nineteen, is contemplating buying the house. And as he says in the last line of the tale: "[t]he play is played out, but need that mean there will never be a repeat performance ...?" (391 elipsis in original). As Hill House still sits brooding, perhaps Shawley Rectory too is still waiting.

\section{Conclusion}

In Rendell's work the mind/body dichotomy is broken down and the gendered divisions rethought in relation to the supernatural. For the poor women ghost-seers discussed here the supernatural occurs in the mind, but is a consequence of curtailed, limited physical and mental lives. But for the mediums and soothsayers there is a blurring of the distinction between the material and the psychic and supernatural. The subtle mix of belief and disbelief that categorises all the encounters with the occult and supernatural in Rendell's work has the 
effect that the depictions of the paranormal seem to err on the side of belief. Perhaps the ritual did work? Perhaps the future can be foreseen and perhaps the body is more attuned to the unseen than the rational mind. For the male ghost-seers this appears to be true and there is a reversion to the body; an insistence on the physicality of the experience of the supernatural. At the beginning of this essay Rendell was quoted as saying that she doesn't believe in ghosts. Yet in her introduction to the collection of M. R. James' ghost stories she writes that if she were to be reading them alone in the house at night, "[a] lot of lights would have to be on and I should prefer to be sitting with my back to the wall" (ix). This is not exactly disbelief. Rendell says that in his reticence and gift of understatement James makes us feel that "[i]t is inconceivable that this learned antiquarian should exceed the bound of strict truth. ... These things must have happened; we believe and believing, put the lights on and our backs to the wall" (xvii). The mind might logically discredit such things, but the body shivers anyway.

Rendell's forays into writing about the supernatural answer no questions and finally refuse to explain anything. As she says of James' work; no explanation is offered, and because of this, "in some contradictory fashion the reader is the more satisfied, the more aghast and disbelief is more securely suspended" (xiii). Rendell saves her actual ghosts, or the perceived manifestation of actual ghosts, for the insane; her poor psychotic characters whose ghosts torment them with the most mundane of hauntings. Yet for the rest; the fortune telling, soothsaying, magic rituals and strange, haunted spaces, there is no explanation, just a subtle suggestion of the melding of the real and the unreal. In her 1987 review of a collection of Rendell crime stories, Hillary Mantel although acknowledging that "Rendell is observant and relentless" (7), critiques the stories for being too conventional and as having "one outcome" (ibid). She says, "[n]ot all malice ends in the mortuary, and perhaps it is a mercy when it 
does; one feels that Ruth Rendell knows this quite well, but is trapped by conventions which - so far - have always made her work less interesting than it might be" (ibid). However her writing about the supernatural allows Rendell space to question many conventions. In her fiction about the paranormal there lingers her refrain of "but yet...": these things might yet be true. And whilst not going as far as James' where "disbelief never put in an appearance" (xii), Rendell plays with and finally deconstructs disbelief at the same time as she questions gendered boundaries and expectations. Sally Munt identifies a 'dissolving sense of reality' (20) in Rendell's work. Her fiction blurs the borders and boundaries that waver between belief and disbelief, reality and unreality, the material and the immaterial. Whilst her forays into the realm of the supernatural carry valid and important critiques of gender relations and other social conventions, the over-riding question focuses around belief. Rendell leads the reader into the very spaces of uncertainty that she herself occupies: questioning just what might possibly exist in the dreaming spaces between heaven and earth.

1 'The Green Road' has also been published under the name 'The Green Road of Quephanda', Rendell, Ruth, (2008), Collected Stories 2, London: Hutchinson. Rendell's short story “The Vinegar Mother” has recently been anthologized in Louise Welsh's book Ghost, (Head of Zeus Publisher, 2015), although this is not strictly a ghost story or even quite supernatural.

2 Mantel wrote a review of a collection of Rendell's stories: Review, “Take One Before Bedtime: Collectedshort stories by Ruth Rendell”. Literary Reveiw, no. 114, 1987. 6-7.

3 There are other male ghost-seers in Rendell's work as well as occult practitioners. Mix in Thirteen Steps Down mistakes a real person for the ghost of the murderer Reginald Christie, 
whilst Diarmit in Killing Doll and Dex in The Saint Zita Society have to grapple with Demons. However these are either explained, or more significant manifestations than those experienced especially by Dolly and Minty.

4 See for example the discussion in Vanessa Dickerson Victorian Ghosts in the Noontide:

Women Writers and the Supernatural, (University of Misouri Press, 1996) 


\section{Works Cited}

Aguirre, Manuel. The Closed Space: Horror Literature and Western Symbolism. Manchester: New York: Manchester U P, 1990.

Brooks, Libby. "Ruth Rendell: Dark Lady of Whodunnits". The Guardian, 3 August, 2002.

Funk, Wolfgang. "Ghosts of Postmodernity: Spectral epistemology and haunting in Hilary Mantel's Fludd and Beyond Black”. Twenty First Century Fiction: What Happens Now?. Sian Adiseshiah and Rupert Hildyard, eds. New York: Palgrave Macmillan, 2013. $147-161$.

The Guardian, "Ruth Rendell reads 'Canon Alberic's Scrapbook' by M. R. James” podcast blurb. 24 December, 2012.

Hazelgrove, Jenny. Spiritualism and British Society Between the Wars. New York: Manchester U P, 2000.

Mantel, Hilary. Review, “Take One Before Bedtime: Collected short stories by Ruth Rendell”. Literary Reveiw, no. 114, 1987. 6-7.

Peterson, Alan, Unmasking the Masculine: 'Men' and 'Identity' in a Sceptical Age, London: Sage Publications, 1998.

Rendell, Ruth. “The Haunting of Shawley Rectory”. 1979. The Virago Book of Ghost Stories. Richard Dalby, ed. London: Virago Press, 2011. 374-391.

---. The Lake of Darkness. London: Arrow Books, 1980.

---. “The Green Road”. 1981. Unforgettable Ghost Stories by Women Writers. Mike Ashley, ed. Mineola, New York: Dover Publications Inc. 2008. 46-63. 
---. The Speaker of Mandarin. 1983. Arrow Books, 1989.

---. The Killing Doll. 1984. London: Arrow Books, 2005.

---. Heartstones. 1987. London: Arrow Books, 1991.

---. Introduction. 1987. M. R. James: Ghost Stories. London: Vintage, 2011.

---. “Computer Seance”. 2000. Collected Stories 2. London: Huthcinson, 2008. 430-439.

---. Adam and Eve and Pinch Me. London: Arrow Books, 2001/2002.

---. Thirteen Steps Down. London: Arrow Books, 2004/2005.

---. The Saint Zita Society. London: Hutchinson, 2012.

Rowland, Susan. From Agatha Christie to Ruth Rendell. New York: Palgrave, 2001.

Rowland, Susan, 'The Horror of Modernity and the Utopian Sublime: Gothic Villainy in P.D. James and Ruth Rendell', in The Devil Himself: Villainy in Detective Fiction and Film, Stacy Gillis and Philippa Gates eds. Westport, Conn: Greenwood Press, 2002. 135-146.

Spooner, Catherine. ““[T]hat Eventless Realm’: Hilary Mantel’s Beyond Black and the Ghosts of the M25”. London Gothic: Place, Space and the Gothic Imagination, Lawrence Phillips and Anne Witchard, eds. London: New York: Continuum, 2010. 8090.

Uglow, Jennifer, 'Introduction', Dalby, Richard (ed), The Virago Book of Victorian Ghost Stories, London: Virago Press, 1992. 
Warner, Marina. Phantasmagoria: Spirit Visions, Metaphor and Media into the Twenty First Century. Oxford: Oxford University Press, 2006. 